\title{
Measuring and mitigating stroke in transcatheter aortic valve implantation: Long roads to the easy answers
}

\author{
John Bozinovski, MD, MSc
}

\footnotetext{
From the Division of Cardiac Surgery, University of British Columbia and the Royal Jubilee Hospital, Victoria, British Columbia, Canada.

Disclosures: Dr Bozinovski was a paid consultant with Edwards Life Sciences LLC

Received for publication Jan 28, 2017; accepted for publication Feb 4, 2017; available ahead of print March 2, 2017.

Address for reprints: John Bozinovski, MD, MSc, 106-2020 Richmond Rd, Victoria, British Columbia, Canada V8R-6R5 (E-mail: john.bozinovski@ubc.ca).

J Thorac Cardiovasc Surg 2017;154:884-5

$0022-5223 / \$ 36.00$

Copyright (c) 2017 by The American Association for Thoracic Surgery

http://dx.doi.org/10.1016/j.jtcvs.2017.02.009
}

Transcatheter aortic valve implantation (TAVI) has rapidly displayed its utility in the treatment of aortic valve disease. While presenting a lesser procedural morbidity and mortality risk, as compared with surgical aortic valve replacement (SAVR), early trials reported higher rates of stroke. ${ }^{1,2}$ To mitigate this complication, cerebral embolic protection (CEP) devices were developed for use in TAVI but there has been limited penetrance into the market. Among the reasons for this are their novelty, relatively low rates of clinically relevant stroke, added complexity of their deployment, cost, and uncertainty of their benefit.

In this issue of the Journal, Drs Messe and Furie ${ }^{3}$ have provided an expert opinion on the use and evaluation of CEP devices during TAVI. They highlight the difficulties inherent in evaluating their utility, given that clinically significant stroke event rates are sufficiently small that large numbers of participants are required to detect significant differences. Although neuroimaging event rates are more easily and objectively detectable, their clinical correlation is not universally, or readily, apparent. Further, the longterm sequelae of strokes should be measured in some way, and accounted for to properly weigh the benefits of using these devices. To address these issues, the ideal studies would be labor intensive, costly, and long term.

As Drs Messe and Furie ${ }^{3}$ have pointed out, quantifying the incidence of stroke is difficult and varies depending on the method of assessment, but it is possible that it occurs more often during TAVI than during open SAVR. If so, and given that TAVI is likely to move to a younger, healthier patient population, the long-term consequence of stroke is even more important. Commensurate is the benefit of preventing stokes in this population. Messe and Furie ${ }^{3}$ summarized 5 trials incorporating 630 patients. ${ }^{4-8}$ Individually, all the trials were small, with only 1 involving more than 100 participants. The studies provided equivocal and sometimes divergent outcomes with respect to protection from stroke, number of infarcts, and/or volume of infarcts, and none provided long-term follow-up because these devices have not been in use until recently. outlined.

\section{References}

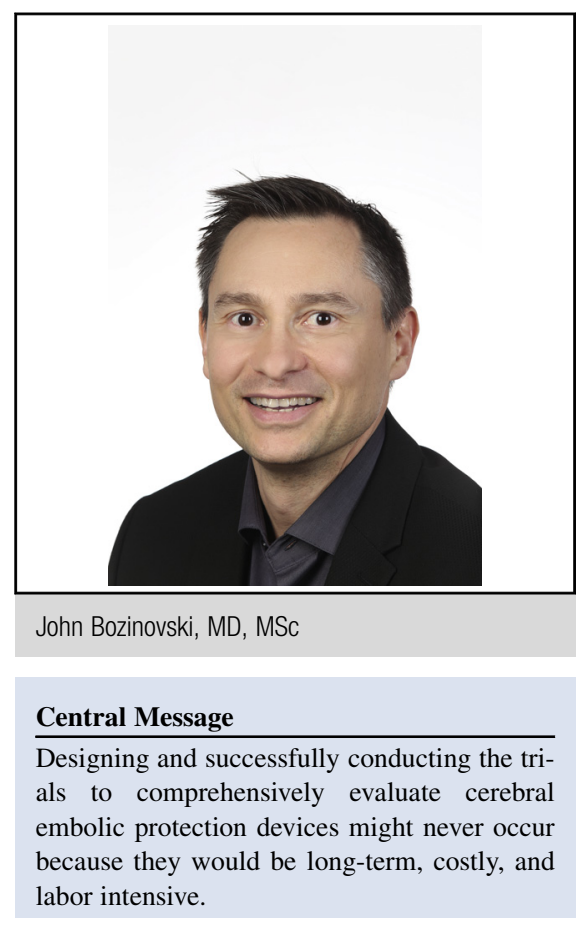

See Article page 880

Although it is valid to argue that the only important outcome for such trials should be clinically significant stroke, rather than diagnostically apparent stroke, we do not yet know the long-term impact of currently silent strokes identified solely on neuroimaging. As such, "clinically significant" stroke carries a nebulous definition.

Perhaps CEP devices will become standard, even without good evidence to support their benefit, or perhaps they will be used infrequently, or not all. Without doubt, the penetrance of these devices will be affected by the quality of the evidence and the size of the treatment effect these devices have. Not only is it difficult to design an effective device, it is possible that we may not know whether a device is effective or what is the size of that effect. Designing and successfully conducting the trial to do so might never occur because of the difficulties Messe and Furie ${ }^{3}$ have well

1. Leon MB, Smith CR, Mack M, Miller DC, Moses JW, Svensson LG, et al Transcatheter aortic-valve implantation for aortic stenosis in patients who cannot undergo surgery. N Engl J Med. 2010;363:1597-607. 
2. Smith CR, Leon MB, Mack M, Miller DC, Moses JW, Svensson LG, et al. Transcatheter versus surgical aortic-valve replacement in high-risk patients. N Engl J Med. 2011;364:2187-98.

3. Messé SR, Furie KL. Cerebral protection for transcatheter aortic valve implantation: A no brainer? J Thorac Cardiovasc Surg. 2017;154:880-3.

4. Samim M, Agostoni P, Hendrikse J, Budde RP, Nijhoff F, Kluin J, et al. Embrella embolic deflection device for cerebral protection during transcatheter aortic valve replacement. J Thorac Cardiovasc Surg. 2015;149:799-805.

5. Wendt D, Kleinbongard P, Knipp S, Al-Rashid F, Gedik N, El Chilali K, et al. Intraaortic protection from embolization in patients undergoing transaortic transcatheter aortic valve implantation. Ann Thorac Surg. 2015;100:686-91.
6. Lansky AJ, Schofer J, Tchetche D, Stella P, Pietras CG, Parise H, et al. A prospective randomized evaluation of the TriGuard HDH embolic deflection device during transcatheter aortic valve implantation: results from the DEFLECT III trial. Eur Heart J. 2015;36:2070-8.

7. Haussig S, Mangner N, Dwyer MG, Lehmkuhl L, Lucke C, Woitek F, et al. Effect of a cerebral protection device on brain lesions following transcatheter aortic valve implantation in patients with severe aortic stenosis: the CLEAN-TAVI randomized clinical trial. JAMA. 2016;316:592-601.

8. Kapadia SR, Kodali S, Makkar R, Mehran R, Lazar RM, Zivadinov R, et al Protection against cerebral embolism during transcatheter aortic valve replacement. J Am Coll Cardiol. 2017;69:367-77. 